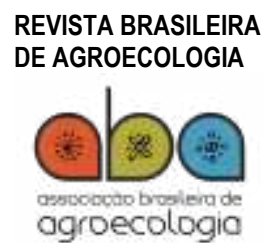

ISSN: 1980-9735

DOI: $10.33240 /$ rba.v14i1.22785

Vol. 14 | №. 1 | p. 16-30| 2019

\title{
SISTEMAS DE PRODUÇÃO DE LEITE DE BASE ECOLÓGICA: A CONSTRUÇÃO DAS VARIÁVEIS A PARTIR DE UMA EXPERIÊNCIA DE EXTENSÃO RURAL EM SANTA MARIA-RS
}

\author{
Milk production systems of ecological base: the construction of variables from an \\ experience of rural extension in Santa Maria-RS
}

Tatiana Aparecida Balem ${ }^{1}$ e Ricardo Lopes Machado ${ }^{2}$

\section{RESUMO}

A atividade leiteira no Rio Grande do Sul está relacionada à agricultura familiar. Esse artigo é baseado em estudo qualitativo que objetiva desenhar as variáveis para o desenvolvimento de sistemas de produção de leite de base ecológica no município de Santa Maria/RS. Foram estudadas sete propriedades produtoras de leite em sistema de Pastoreio Rotativo Voisin (PRV). A experiência trata de um processo de extensão rural diferenciado. As categorias de análise são: PRV, manejo de agroecossistemas, manejo agroecológico de solos, bem-estar animal, relação ser humano-natureza e reprodução social. Os principais avanços percebidos foram o aumento da renda, sistemas sustentáveis de produção e diminuição da penosidade do trabalho. A transição agroecológica dos sistemas de produção de leite de Santa Maria demonstra duas questões centrais: 1) Os referenciais que compõem o sistema agroecológico; 2) A importância de uma extensão rural capaz de realizar uma ruptura e a libertação dos agricultores dos sistemas de produção convencionais, bem como de estabelecer processos contínuos em vez de uma ação fragmentada e pontual.

Palavras-chave: Agricultura Familiar, Produção Leiteira, Agroecologia.

1 Instituto Federal Farroupilha campus Júlio de Castilhos-RS

E-mail: tatianabalem@yahoo.com.br

${ }^{2}$ Emater-RS/ASCAR.

E-mail: ricardol.machado@hotmail.com.

Recebido em:

18/07/2018

Aceito para publicação em:

25/03/2019

Correspondência para:

ricardol.machado@hotmail.com

\section{ABSTRACT}

Milk activity in Rio Grande do Sul is related to family agriculture. This article is based on a qualitative study that aims to design the variables for the development of ecologically based milk production systems in the municipality of Santa Maria/RS. Seven milk producing properties were studied in a Voisin Rotating Grazing (PRV in portugues) system. The experience is about a process of differentiated rural extension. The categories of analysis are: PRV, agroecosystem management, agroecological management of soils, animal welfare, human-nature relationship and social reproduction. The main advances perceived were increased income, sustainable production systems and reduced labor pains. The agroecological transition of the Santa Maria milk production systems demonstrates two key questions: 1) The references that make up the agroecological system; 2) The importance of a rural extension capable of achieving a rupture and the liberation of farmers from conventional production systems, as well as establishing continuous processes instead of a fragmented and punctual action.

Keywords: Family Agriculture, Milk Production, Agroecology. 

Introdução

O objetivo desse trabalho é apresentar e discutir as bases da produção ecológica de leite, tendo como referência a análise de um processo de extensão rural desenvolvido no município de Santa MariaRS (SM).

Além dessa introdução, na segunda parte do trabalho, mostramos os caminhos metodológicos e na terceira parte, encontra-se a construção teórica que referencia os sistemas agroecológicos de produção de leite e o cotejamento com a base empírica. A partir da análise da base empírica, criamos seis categorias de análise e realizamos esforço de não descolamento entre a teoria e o empírico. Na introdução da seção três é apresentado breve panorama da produção leiteira no Brasil e Rio Grande do Sul. Também é apresentado o processo de extensão rural em desenvolvimento em SM com os agricultores produtores de leite. A primeira categoria de análise traz a base teórica do Pastoreio Racional Voisin (PRV) que funciona como "pano de fundo" para a conversão dos sistemas de produção de leite em agroecológicos. São explorados dados técnicos e econômicos de propriedades estudadas, a partir do início da conversão dos sistemas. Na segunda categoria de análise apontamos a importância do manejo dos agroecossistemas, ou seja, extrapolamos a visão para além do sistema de produção de leite. O manejo ecológico de solos poderia ter sido trabalhado juntamente com o manejo dos agroecossistemas. Porém, em virtude da importância desse para o êxito da conversão agroecológica e pelos limites identificados na base empírica, achamos por bem trabalhar como uma categoria específica. O bem-estar animal é discussão imprescindível nos sistemas agroecológicos de produção de leite, sendo a fitoterapia e a homeopatia recursos complementares na promoção da sanidade animal.

As categorias de análise "relação ser humano-natureza" e "reprodução social" demonstram que o sistema de produção não acontece à revelia dos agricultores. Na primeira categoria, exploramos a mudança de atitude, percepção e vivência dos agricultores, quando imersos no processo de transição agroecológica. Já na segunda, buscamos tecer a relação entre os sistemas de produção de base ecológica e o fortalecimento da agricultura familiar. Essas duas últimas categorias situam o agricultor como protagonista do processo, pois, segundo a ideia base da extensão adotada, os agricultores "fazem e sabem por que fazem". Assim, o desenvolvimento de habilidades, o aprimoramento dos conhecimentos já enraizados e a participação dos agricultores em todo o processo são primordiais. Por fim, as considerações fazem um breve apanhado das principais ideias discutidas na seção três desse artigo.

\section{Metodologia}

Esse trabalho é um estudo qualitativo desenvolvido a partir da análise de uma experiência de Assistência Técnica e Extensão Rural (ATER), que tem por meta promover a transição dos sistemas de produção de leite convencionais para sistemas de base ecológica. O método de pesquisa pode ser definido como um estudo de caso. A experiência de extensão rural analisada está em andamento no município de Santa Mmaria-RS (SM) desde 2010 e é coordenada pelo Escritório Municipal (EM) da Emater-RS. Santa Maria está localizado no Centro Geográfico do Rio Grande do Sul, em uma área de transição morfológica denominada Rebordo do Planalto, entre dois conjuntos fisiográficos, os quais estão representados pelo Planalto Meridional Brasileiro e a Depressão Central do Rio Grande do Sul. O clima do município é classificado como subtropical Cfa (Classificação de Köppen), ou seja, clima temperado húmido sem estação seca e com verão quente.

Os instrumentos de coleta de dados utilizados foram a observação realizada desde a implantação do projeto até 2016. Um dos autores é o extensionista responsável pelo processo de extensão desenvolvido; a análise de um diagnóstico realizado pelo EM da Emater-RS com os produtores de leite de SM em 2010; entrevista em profundidade com sete agricultores e análise dos dados técnicos e econômicos de duas propriedades. As entrevistas em profundidades foram gravadas e, posteriormente, transcritas. A categorização das entrevistas foi estabelecida a partir da análise das mesmas, incialmente esperava-se abordar as categorias Pastoreio Rotativo Voisin (PRV), manejo de 
agroecossistemas e bem-estar animal, mas o campo nos mostrou outros caminhos. Desta forma as bases da produção de leite de base ecológica estão expressas em cinco categorias: PRV; manejo de agroecossistemas, manejo ecológico do solo, bem-estar animal, relação ser humano natureza e reprodução social.

A análise qualitativa foi orientada pela análise interpretativa. Para Gomes (2012) a análise interpretativa busca a lógica interna dos fatos, dos relatos e das observações e os situa no contexto dos atores. Para essa análise, seguimos ao que Gomes (2012) recomenda: 1) A montagem da estrutura de análise e categorização dos conteúdos. Essa categorização foi dinâmica e a etapa seguinte de exploração do material foi realizada através da interpretação e paráfrase das falas registradas nas entrevistas; 2) Exploração do material. Para esse fim, identificamos as ideias implícitas e explícitas nas entrevistas, buscando os sentidos mais amplos, atribuídos às ideias. A partir dessa fase construímos as categorias de análise presentes neste artigo; e 3) A elaboração do documento final. Ou seja, articulamos os objetivos com a base teórica e os dados empíricos, como afirma ser necessário Gomes (2012).

\section{As bases da produção ecológica de leite}

O leite tornou-se uma das bebidas mais consumidas no mundo, servindo, também, de matéria prima para a confecção de muitos outros produtos, sendo de suma importância para economia do país. O Brasil é o quarto maior produtor mundial de leite (FAO, 2017) e este é o sexto produto nacional com maior valor bruto de produção (MAPA, 2018). A Agricultura Familiar tem forte expressão na cadeia leiteira brasileira com a participação de $56,4 \%$ na produção total (FRANÇA et al., 2009).

A região Sul do Brasil produz 32\% da produção nacional leiteira (MAIA et al, 2013). No estado do Rio Grande do Sul (RS), em 2015, a produção de leite estava presente em 198.467 propriedades no estado, sendo que 84.199 produtores vendiam leite cru para indústrias, cooperativas, queijarias ou processavam em indústria própria legalizada, o que equivale a $42,4 \%$ do total de produtores de leite (IGL e EMATER-RS, 2015). No entanto, em 2017, foi observado que a produção leiteira estava presente em 173.706 propriedades e em torno de 65 mil famílias vendem leite cru para a indústria ou processam, sendo 19 mil famílias a menos do que indicavam os números de 2015 (EMATER-RS, 2017, p. 17)., conforme afirma que "os produtores de leite no RS possuem propriedades com área média estimada na pesquisa em 19,1 hectares, o que demonstra que a produção de leite no Estado é predominantemente desenvolvida em pequenas e médias propriedades" (EMATER-RS, 2017, p. 18). Dos agricultores que comercializam o leite no RS, $99 \%$ são agricultores familiares "expressando de forma muito significativa a importância social dessa atividade pecuária" (EMATER-RS, 2017, p. 22). Ainda relativo a este grupo que comercializa o leite formalmente, os dados indicam que $23,9 \%$ (em 2015) e 17,9 \% (em 2017) dos produtores encontram-se na faixa de menor volume diário de produção (até 50 litros/dia). Na faixa até 100 litros/dia teríamos aproximadamente $45 \%$, em 2015, e 37,8\%, em 2017, do total de produtores. Por outro lado, apenas 15,2\%, em 2015, e 18,2\%, em 2017, dos produtores produzem mais que 300 litros/dia (EMATER-RS, 2017; IGL e EMATER-RS, 2015). Por esses dados, percebe-se que a maioria dos produtores possuem reduzida escala de produção, sendo o grupo que mais abandonou a atividade entre 2015 e 2017. Por outro lado, observa-se um ligeiro aumento da porcentagem de famílias que produzem de 100 a 300 litros e mais de 300 litros diários. Desse modo, é fundamental que se proponham tecnologias apropriadas a estes pequenos agricultores, visando a sua reprodução social e permanência no campo, sendo que o sistema de produção de leite de base ecológica se desafia a isso.

Segundo levantamentos realizados pelo EM da Emater-RS de Santa Maria, a atividade leiteira vem decrescendo em número de produtores ao longo do tempo no município. Porém, a produção total de leite se mantém estável, o que denota uma maior especialização dos agricultores que conseguem persistir na atividade. No início da década de 1990, existiam em torno de 300 agricultores que se dedicavam à atividade leiteira comercializando sua produção à indústria, atualmente são apenas 35 famílias. 
Em 2010, o Escritório Municipal (EM) de Emater-RS de Santa Maria, iniciou um processo de discussão dos sistemas de produção de leite com as famílias agricultoras envolvidas com a atividade. Inicialmente, o objetivo deste trabalho era implantar Unidades de Referência (UR) de produção de leite à base de pasto, sendo o Pastoreio Racional Voisin (PRV) a tecnologia norteadora. O EM da Emater-RS buscou desenvolver uma proposta de ação extensionista que pudesse superar os gargalos desse modelo produtivo, que haviam sido identificados por meio de um diagnóstico realizado pelo extensionista envolvido.

Esse diagnóstico identificou que a base do sistema de produção de leite encontrado no município de Santa Maria era a utilização de altas quantidades de concentrado comercial como forma de suplementação da alimentação volumosa; utilizavam silagem de milho (Zea mays); as pastagens utilizadas eram predominantemente com espécies anuais, principalmente milheto (Pennisetum glaucum) e sorgo forrageiro (Sorghum spp) que demandam maquinário, intenso manejo do solo e compra periódica de sementes; uso de fertilizantes químicos; várias propriedades utilizavam a suplementação alimentar no cocho com cana de açúcar e mandioca, o que exige um trabalho árduo e penoso da família. Esse sistema gerava um "ciclo vicioso" de custos de produção, pois a maioria das famílias, por estarem descapitalizadas, parcelava o pagamento do pacote tecnológico, assim, quando acabava de pagar o pacote de insumos do verão, começava a pagar o pacote de inverno.

As tecnologias adotadas pelos produtores de leite gaúchos evidenciam a dependência da produção leiteira com base em pastagens anuais e uso de silagem. Segundo a EMATER-RS (2017), 96,3\% dos produtores utilizam pastagem anual de inverno. Também é muito expressiva a utilização das pastagens anuais de verão, que estão presentes em $85,5 \%$ das propriedades e o uso de silagem para a alimentação do rebanho leiteiro no verão ou no inverno (84,5\%). Seramim e Rojo (2016), em análise econômica de duas propriedades com sistema convencional de leite observaram margens de custos de produção de $90 \%$ e $77 \%$. Pila e Ribeiro (2018) afirmam que a queda do preço do leite no ano de 2017 e o aumento dos custos de produção resultaram em muitos agricultores com lucratividade negativas. Para Seramim e Rojo (2016), esse modelo de produção com alto custo variável é mais adequado para produtores de médio o grande porte. Desta forma, para a agricultura familiar é imprescindível a busca de novos referenciais tecnológicos para que a mesma não seja excluída da cadeia produtiva.

Outra questão apontada pelo diagnóstico dos produtores de leite de Santa Maria refere-se à sanidade do rebanho, sendo a alta incidência de mastite e altas infestações de carrapatos (Rhipicephalus microplus) os principais problemas. Peres Neto e Zappa (2011, p. 02) afirmam que "A mastite é a inflamação da glândula mamária que se caracteriza por apresentar alterações patológicas no tecido glandular e uma série de modificações físico-químicas no leite". Segundo Acosta et al. (2016), a prevalência da mastite subclínica chega a $48,64 \%$ na espécie bovina, sendo que o principal agente causal, a bactéria Staphylococcus spp., apresenta alto percentual de resistência a princípios ativos de antibióticos. Os fatores de risco associados à ocorrência de mastite estão relacionados a problemas no saneamento ambiental e ao manejo dos animais (ACOSTA et al, 2016). A alta incidência de mastite resultava em descarte de leite periódico e prejuízo aos agricultores.

A alta incidência de carrapatos observada resultava em aplicações de carrapaticidas químicos de forma quinzenal no verão e, em algumas propriedades, ocorria aplicação semanal. Segundo Kohek Junior (2015), o pico de infestação deste parasita ocorre nos meses de dezembro e janeiro. Esse autor ainda salienta que a maioria dos métodos de controle químicos utilizados tem resultado em baixa eficácia e resistência do ectoparasita. Os principais problemas relacionados ao carrapato são a transmissão da doença Tristeza Parasitária Bovina e a irritação e estresse que o ectoparasita causa nos animais.

Percebe-se que o sistema convencional de produção de leite utilizado em Santa Maria, resulta em sistema dependente em insumos químicos, com alto custo de produção e com problemas de ordem tecnológica expressivos. $\mathrm{O}$ sistema de base ecológica que será discutido a seguir e está em implantação em várias propriedades no município, se propõe a superar esses gargalos técnicos e produtivos, assim como demonstrar uma possibilidade de superação do modelo de agricultura herdeiro do processo de modernização baseado em pacotes tecnológicos. 
Pastoreio Racional Voisin (PRV)

O Pastoreio Racional Voisin, é a tecnologia desenvolvida pelo Francês André Voisin, a fim de aumentar a produtividade e o valor biológico das pastagens, além de ser capaz de aumentar progressivamente a fertilidade do solo, produzir alimentos mais limpos e de alto valor biológico, além de respeitar o bem-estar dos animais (PINHEIRO MACHADO, 2004). O sistema aumenta os ganhos na criação dos animais, pois produz, no mínimo, três vezes mais pastos e, assim, três vezes mais leite do que a média da região onde se está trabalhando (PINHEIRO MACHADO, 2004). Um dos princípios do PRV é o uso de pastagens de acordo com as características ecossistêmicas da região, preservando ou implantando arbóreas que visam o equilíbrio do agroecossistema e o bem-estar animal (Ibidem). Com o PRV é possível baixar o custo de produção, pois a matéria seca produzida pela pastagem é mais barata e sustentável do que a encontrada em alimentos comerciais concentrados ou silagem. Assim, os principais "insumos" do sistema são o conhecimento sobre o manejo do agroecossistema, o esterco, a urina das vacas e a energia solar (PINHEIRO MACHADO, 2004).

O PRV se baseia, fundamentalmente, na divisão da área de pastoreio em um número mínimo de piquetes, que possibilite ao agricultor o adequado manejo dos animais, respeitando, assim, as quatro leis universais estabelecidas por André Voisin e discutidas por Pinheiro Machado (2004). As duas primeiras leis são relativas ao manejo dos pastos e as duas seguintes ao manejo dos animais: 1) A "Lei do Repouso" estabelece que entre um corte e outro é necessário um tempo mínimo de aproximadamente 30 dias para que a pastagem armazene nas suas raízes as reservas necessárias para um próximo rebrote vigoroso; 2) Segundo a "Lei da Ocupação" o tempo global de ocupação de uma parcela deve ser o suficientemente curto para que o rebrote do pasto não seja cortado duas vezes no mesmo período de ocupação, ou seja, de 1 a 3 dias, sendo o ideal um dia; 3) A premissa da "Lei do rendimento máximo" parte de que os animais precisam colher a maior quantidade de pasto na melhor qualidade possível; 4) Por fim, a Lei do rendimento regular, trata da necessidade de regularidade na produção animal o ano inteiro, que se atinge com a permanência máxima de um dia por parcela, no caso do rebanho leiteiro.

Para que se respeitem as leis universais do PRV é fundamental ter um número mínimo de piquetes. Para a região de SM, pela experiência do projeto que estamos estudando e considerando as características edafoclimáticas e de solo, são utilizados em torno de 50 piquetes e pastejo de um dia. Esse número foi estabelecido em função da observação dos sistemas de produção dos agricultores e considera as seguintes variáveis que são praticadas pelos agricultores estudados: 1) Quanto maior o número de piquetes melhor será o manejo, em épocas de abundância de forragem, como na primavera, os agricultores usam dois piquetes por dia, melhorando, assim, a produtividade dos animais, e utilizam a roçada da sobra da pastagem como forma de adição de matéria orgânica no solo, alguns agricultores ainda utilizam piquetes sem pastoreio para fazer feno; 2) Em época de menor oferta de forragem, como na transição das forragens de inverno-verão e verão-inverno, os agricultores utilizam dois piquetes por dia, garantindo, dessa forma, o rendimento regular, presente na quarta lei do PRV. Se tivermos apenas 30 piquetes com ocupação de um dia, em uma época de estiagem ou de transição de pastagem verãoinverno, a pastagem não estará recuperada e no seu ponto ótimo de repouso quando os animais voltarem ao pastoreio.

Quanto às pastagens, busca-se a implantação de espécies forrageiras adaptadas à região, partindo sempre do princípio que o agroecossistema deve ser o mais próximo possível do ecossistema natural (GLIESSMAN, 2000; ALTIERI, 2012). No caso de áreas já degradas pelo manejo convencional do solo, onde se tinha sucessivos anos de cultivos anuais, são utilizadas espécies perenes que possuam desenvolvimento rápido para a cobertura de solo e valor forrageiro expressivo, como por exemplo, as gramíneas tifton (Cynodon spp), Missioneira Gigante (Axonopus compressus) e Hemarthria (Hemarthria altíssima). Estas são implantadas de forma vegetativa. A gramínea pensacola (Paspalum notatum) é implantada via semente e em algumas áreas foi utilizada pelos agricultores em função da facilidade da formação da pastagem, no entanto é de menor valor forrageiro para o sistema de produção de leite, embora seja uma pastagem bem adaptada às condições de clima e de solo, por ser nativa da região. As leguminosas que estão sendo utilizadas são amendoim forrageiro (Araquis spp), trevo branco (Trifolium 
repens) e trevo vesiculoso (Trifolium visiculosum). Os trevos apresentam problema de povoamento, visto que são forrageiras exigentes em fertilidade. A estratégia que está sendo utilizada com maior grau de sucesso nas propriedades estudadas é o "plantio via bosta", onde se fornece as sementes misturadas ao concentrado ou ao sal mineral. Essa técnica garante a quebra da dormência da semente via sistema digestivo e um nicho de fertilidade natural proporcionado pelo esterco. Não se preconiza, com as pastagens implantadas, a monocultura dessas forrageiras, sendo que em muitas áreas os agricultores consorciam várias espécies. Com o manejo realizado, observa-se que o banco de sementes das espécies nativas presentes no solo recebe condições adequadas para se estabelecer nas áreas de pastagem implantadas, atingindo, assim, uma composição do dossel forrageiro de espécies nativas mescladas com as plantas introduzidas.

De acordo com Pinheiro Machado (2004), a utilização de pastagens tropicais permite a produção de forragem de boa qualidade em climas subtropicais. No entanto é necessário a utilização de espécies forrageiras de clima tropical durante os meses mais quentes do ano e espécies de clima temperado durante os meses mais frios. Assim, nas propriedades em Santa Maria-RS, as pastagens são compostas por espécies tropicais perenes com sobressemeadura de espécies anuais de clima temperado. No período entre os meses de março e abril, os agricultores fazem a sobressemadura de aveia preta (Avena strigosa) e azevém (Lolium Multiflorum).

A sobressemeadura é relizada diariamente antes da entrada dos animais nos piquetes. Após a sobressemeadura, os animais pisoteiam a área, colocando as sementes em contato com o solo. Recomenda-se roçar a área depois da saída dos animais para cobrir melhor as sementes. Com esta técnica a área de pastoreio possui pastagem o ano inteiro, praticamente eliminando os vazios forrageiros que, normalmente, acontecem na mudança da estação quente para a estação fria e viceversa. Nesses períodos, é necessário em torno de 40 dias de descanso para o retorno dos animais ao piquete, o que justifica a necessidade de 50 piquetes, para garantir a permanência média de um dia do lote de animais no piquete, possibilitado um manejo adequado das pastagens e animais, respeitando, assim, as leis universais de Voisin. O manejo de troca de piquete é feito depois da ordenha da tarde, pois o período da noite é o momento em que os animais mais pastam, especialmente no verão.

O modelo de divisão preconizado é com piquetes quadriláteros, que favorecem um pastoreio homogêneo da área e diminuem a dominância entre os animais. Os corredores são perimetrais e não centrais, distribuindo, dessa maneira, a caminhada das vacas na área, evitando erosão e servindo de barreira biológica na divisa com vizinhos (PINHEIRO MACHADO, 2004). Esse desenho de divisão facilita a distribuição da rede hidráulica. Nos projetos implantados há disponibilização de água em todos os piquetes, através de bebedouros móveis que acompanham a rotatividade dos animais. Desse modo, os animais conseguem beber água em quantidade suficiente e com qualidade, em momentos diferentes do dia, evitando-se a dominância que alguns bovinos exercem sobre outros no momento em que são direcionados coletivamente para bebedouros. A disponibilidade de água nos piquetes gera um aumento de rendimento de 10 a 20\% de produção de leite (PINHEIRO MACHADO, 2004).

As raças Holandesa e Jersey são as mais utilizadas pelos agricultores desta experiência, pelo potencial de produção e adaptação às condições climáticas. No sistema de produção de base ecológica preconizam-se raças mais adaptadas e mais rústicas, portanto tem-se recomendado o cruzamento da raça Holandesa com a raça Jersey, que segundo Cassell e Mcallister (2009) resultam em melhoria no teor de sólidos do leite, fertilidade, longevidade e facilidade de parto, além da redução dos problemas de consanguinidade. A maior parte dos cruzamentos entre raças leiteiras especializadas têm como base - Holandês, superior em produção de leite, e Jersey, conhecido pela alta concentração de sólidos no leite, rápida maturidade e maior fertilidade (THALER NETO et al., 2013). No entanto, os agricultores têm demonstrado certa resistência em adotar esse sistema e tendem a preferir as raças puras. Hoje, em torno de $40 \%$ dos agricultores de Santa Maria que estão em processo de implantação da produção de leite de base ecológica fazem o cruzamento e das sete famílias desta pesquisa apenas dois o fazem.

Outra prática é o planejamento de uma área destinada à criação das terneiras e que serve de "escola" para as mesmas. Neste "mini PRV" essas já crescem acostumadas com o sistema, ficam mais dóceis e saudáveis. 
A gestão é outro aspecto fundamental da experiência em andamento, tanto a gestão do manejo do agroecossistema, como a gestão econômica. No primeiro caso o processo é facilitado, pois com a divisão da área em piquetes, o agricultor consegue "enxergar melhor" a sua área, dando uma atenção especial para cada um dos piquetes, pois com o tempo, cada um deles cria a sua "personalidade" própria. Como afirma um agricultor: "agora ficou bom de olhar a pastagem, a gente vai ali e vê, se o pasto ainda não está bom naquele piquete coloca em outro mais para frente e depois retorna, assim as vacas têm sempre pasto de boa qualidade". No aspecto econômico, preconiza-se o gerenciamento das receitas e despesas (custos fixos e variáveis) da atividade, sendo que cada propriedade tem um caderno de gestão. $O$ índice econômico é a renda líquida por hectare (ha) trabalhado, pois praticamente todas as atividades agrícolas se baseiam nesse parâmetro. Esse índice proporciona aos agricultores compararem sistemas de produção praticados na região. Outro agricultor comenta: "outra coisa boa é poder acompanhar os números, antes a gente não sabia quanto rendia e quanto custava, teve meses que eu acho que tive prejuízo, mas não sei porque não acompanhava. A gente não tinha o costume de fazer isso."

Nas Tabelas 01 e 02 seguem os dados produtivos e econômicos de duas propriedades pesquisadas. Percebe-se que a renda líquida/ha e a renda mensal aumentaram, sensivelmente, nas duas propriedades, havendo um acréscimo anual conforme o sistema vai se estabilizando. Esses parâmetros são representativos das outras propriedades acompanhadas no município.

Tabela 01 - Dados técnicos e econômicos ao longo de cinco anos da Propriedade 1.

\begin{tabular}{lccccr}
\hline \multicolumn{1}{c}{ Ano } & $\begin{array}{c}\text { Produção } \\
\text { Total (Litros) }\end{array}$ & $\begin{array}{c}\text { Produção } \\
\text { Mensal Média (Litros) }\end{array}$ & $\begin{array}{c}\text { Custo de } \\
\text { produção }\end{array}$ & $\begin{array}{c}\text { Renda mensal líquida } \\
\text { (R\$)*** }\end{array}$ & $\begin{array}{c}\text { Renda líquida/ } \\
\text { ha/ano (R\$)*** }\end{array}$ \\
\hline 2010 & 39.600 & 3.300 & $66 \%$ & $1.083,01$ & 649,81 \\
2011 & 60.260 & 5.021 & $64 \%$ & $1.891,81$ & $1.850,62$ \\
2012 & 105.093 & 8.758 & $52 \%$ & $5.239,33$ & $5.123,79$ \\
$2013^{*}$ & 62.721 & 5.227 & $41 \%$ & $5.309,51$ & $6.109,11$ \\
2014 & 78.000 & 6.500 & $44 \%$ & $6.567,42$ & $7.557,74$ \\
$2015^{* *}$ & 57.140 & 4.762 & $51 \%$ & $2.843,04$ & $6.204,07$ \\
\hline
\end{tabular}

* Em 2013 a produção baixou em função da venda de animais no início do ano.

**Em 2015 a renda líquida mensal diminui porque a área total explorada diminuiu de 10, 5 para 6 hectares.

*** Valores corrigidos considerando o período de dezembro dos anos de acompanhamento a março de 2019 pelo índice IGP-M (FVG).

Tabela - Dados técnicos e econômicos ao longo de seis anos da Propriedade 2.

\begin{tabular}{rcccrc}
\hline Ano & $\begin{array}{c}\text { Produção } \\
\text { Total (Litros) }\end{array}$ & $\begin{array}{c}\text { Produção } \\
\text { Mensal Média (Litros) }\end{array}$ & $\begin{array}{c}\text { Custo de } \\
\text { produção }\end{array}$ & $\begin{array}{c}\text { Renda mensal } \\
\text { líquida (R\$)* }\end{array}$ & $\begin{array}{c}\text { Renda líquida/ } \\
\text { ha/ano (R\$)* }\end{array}$ \\
\hline 2010 & 159.400 & 13.283 & $50 \%$ & $8.098,33$ & $2.429,50$ \\
2011 & 164.189 & 13.682 & $55 \%$ & $7.370,45$ & $2.210,68$ \\
2012 & 201.817 & 16.818 & $58 \%$ & $8.230,58$ & $2.469,17$ \\
2013 & 212.973 & 17.747 & $59 \%$ & $9.181,90$ & $2.757,77$ \\
2014 & 250.000 & 20.800 & $50 \%$ & $13.030,59$ & $4.430,40$ \\
2015 & 294.000 & 24.500 & $53 \%$ & $14.163,42$ & $4.248,67$ \\
2016 & 320.297 & 26.691 & $46 \%$ & $21.552,19$ & $6.474,94$ \\
\hline
\end{tabular}

* Valores corrigidos considerando o período de dezembro dos anos de acompanhamento a março de 2019 pelo índice IGP-M (FVG).

Na propriedade 01, em 2015, a renda líquida mensal diminui porque a área total explorada diminuiu de 10,5 para 6 hectares, pois a família deixou de arrendar uma área e passou a utilizar somente a área própria. Outro parâmetro importante é que os custos de produção tendem a diminuir com o PRV. No entanto, na propriedade 02 observa-se um aumento dessa variável, em 2012 e 2013 isso se deve ao uso de silagem e ao alto investimento em maquinários na propriedade neste período, o que incidiu em aumento do valor relativo à depreciação dos equipamentos. Na propriedade 02, a suplementação com silagem é necessária porque a área de pastagem com sistema PRV ainda não fornece a quantidade de matéria seca necessária para o plantel existente, o sistema ainda não atingiu o 
seu equilíbrio dinâmico. Em 2014, com o aumento de produção e com o sistema mais equilibrado, houve diluição dos custos de produção.

\section{Manejo de agroecossistemas}

O processo de transição agroecológico pretendido com a mudança das bases do sistema de produção de leite requer uma compreensão dos agricultores para além da atividade agrícola. Partimos do conceito de agroecossistemas de Gliessman (2000), no qual o local de produção agrícola é compreendido dentro de um ecossistema natural, sendo que as variáveis e componentes desse último impactam o primeiro.

A unidade de análise que utilizamos são as propriedades rurais, mas buscamos entender os sistemas de produção de leite em SM a partir do ecossistema e da ação antrópica, para compreender as variáveis ambientais. As principais mudanças pretendidas são: a desmistificação do padrão modernizante, intensivo em agroquímicos e insumos externos; a possibilidade de diminuir a penosidade do trabalho, aumentar a renda e garantir sustentabilidade da atividade, a partir do redesenho dos agroecossistemas; o resgate e/ou valorização da interação entre o ser humano e a natureza, que será discutido na seção 3.5. Alguns conhecimentos e habilidades precisaram ser mobilizados e a observação acurada das mudanças, realizada pelos agricultores, se fez imprescindível.

De acordo com Altieri (2012), para o desenvolvimento de sistemas de produção agroecológicos é necessária a compreensão das relações e processos ecológicos, para que os agroecossistemas possam ser manipulados de forma a produzir de modo mais sustentável, com menos impactos ambientais e utilização de insumos externos. O primeiro passo na problematização do manejo dos agroecossistemas foi a discussão e implementação das bases do PRV. O segundo passo foi compreender as características do solo e a necessidade de um manejo conservacionista, embora o solo seja um dos componentes do manejo dos agroecossistemas. A terceira questão trabalhada nesse processo foi a implantação de arbóreas nas pastagens para no médio prazo obter sistemas silvipastoris, "uma modalidade de agrofloresta que se caracteriza por integrar componentes lenhosos (árvores e arbustos), herbáceos (gramíneas e leguminosas) e animais herbívoros" (CARVALHO e XAVIER, 2005, p. 499). O sistema silvipastoril é preconizado por três motivos: pelos ganhos ambientais, por procurar desenvolver um sistema de produção mais parecido com o ecossistema local; em função do bem-estar animal; por oferecer ganhos econômicos extras aos agricultores com a futura extração de madeiras ou subprodutos.

Segundo Altieri (2012), um conjunto de plantas, com diferentes hábitos, dosséis e estruturas radiculares, permitem um melhor uso dos insumos ambientais. Ao desenvolver uma atividade agrícola mais próxima possível do ecossistema, se busca aumentar a resiliência dessa perante impactos ambientais, além disso, esse equilíbrio dinâmico irá auxiliar no controle de pragas e doenças (ALTIERI e NICHOLLS, 2013). Os sistemas silvipastoris podem desempenhar papel preponderante no estabelecimento de corredores biológicos, promovendo o intercâmbio de genes entre populações, interligando fragmentos vegetais dispersos e isolados (FRANKE e FURTADO, 2001). A reciclagem de nutrientes merece ser destacada, pois o componente arbóreo recicla nutrientes das camadas mais profundas do solo e disponibiliza para a pastagem através da serapilheira. Outro aspecto é o controle da erosão e maior aproveitamento da água da chuva, nesses sistemas.

O segundo ganho refere-se ao bem-estar animal, pois nos períodos do ano em que as temperaturas são altas, os animais necessitam de pastos sombreados e nos períodos de inverno e chuvas, de abrigo. "Esses fatores de conforto se refletem, também, no desempenho produtivo e reprodutivo dos animais" (CARVALHO e XAVIER, 2005, p. 500). Carvalho e Xavier (2005) salientam haver estudos indicando que em situações de altas temperaturas há incremento de até $35 \%$ de matéria seca da pastagem de áreas em sistema silvipastoril, quando comparadas com pastagens em pleno sol. Por outro lado, se fizermos uma analogia com a teoria da trofobiose de Chaboussou (1999), os animais com conforto térmico, somado à alimentação de qualidade e manejo adequado, apresentam maior bemestar e este garante um organismo mais equilibrado, por isso menos suscetível à ataques de parasitas e doenças. 
Esse componente está em processo de implantação das propriedades, mas já se observam melhorias relatadas pelos agricultores, tais como menor incidência de carrapatos e inflamações mamárias.

\section{Manejo ecológico de solos}

Entender e conhecer o solo, como um sistema vivo e complexo, composto por vários elementos que vão desde a micro, meso e macrofauna, componentes minerais e interações tróficas são base para o manejo ecológico dos solos. De acordo com Primavesi (1999, p. 258), o solo "é um sistema dinâmico de complexas inter-relações recíprocas entre seus componentes físicos, químicos e biológicos" e não somente suporte para plantas e adubos, muito menos rocha moída com alguns elementos em solução.

A compreensão de que as cadeias tróficas de biotransformação vão gerar os nutrientes para o pleno desenvolvimento dos vegetais. Neste caso estudado, das pastagens, é básico para os agricultores entenderem e realizarem o manejo ecológico dos solos. Percebemos que antes os agricultores acreditavam que os nutrientes necessários para as pastagens eram disponibilizados via adubos químicos. Nas pastagens nativas, não utilizavam qualquer fertilizante, num entendimento que somente as culturas anuais necessitavam de adubação. Assim, em praticamente todas as propriedades estudadas, observamos que as áreas de campo nativo não recebiam qualquer tipo de fertilização ou de manejo que propiciasse produtividade animal satisfatória. Como campo nativo nos referimos à formação natural presente no Bioma Pampa no RS (OVERBECK et al., 2009). Esse bioma é predominante no município de Santa Maria, sendo bioma constituído de amplas áreas de pastagens naturais.

Os sistemas de produção de leite, antes do processo de transição agroecológica, eram basicamente desenvolvidos com revolvimento do solo e uso de adubos químicos. Isso gerou condições de solo extremamente degradadas, com problemas de erosão e de estrutura, baixa fertilidade e porcentagem de matéria orgânica. Essas condições fazem com que o processo de recuperação do solo seja mais demorado, muitas vezes necessitando da utilização de fertilizantes externos ao agroecossistema nos primeiros anos. Outro agravante é a alta acidez dos solos, que vem sendo solucionada com calagem, prática que não era utilizada pelos agricultores.

A indisponibilidade de adubos orgânicos na região dificulta a substituição do insumo químico preconizada no manejo ecológico dos solos. Uma das ações para sanar esse problema tem sido a organização da compra coletiva de adubo orgânico, que vem de regiões cerca de 400 quilômetros distantes. Em função dessa dificuldade para encontrar adubos orgânicos e da necessidade de aporte de fertilizantes enquanto não se alcança o equilíbrio do sistema, os agricultores ainda utilizam, em situações específicas, fertilizantes químicos. No entanto, o que se observa é uma diminuição da quantidade de fertilizantes químicos utilizada na maioria das propriedades ao longo do processo. Um agricultor afirma que diminuiu em $50 \%$ o uso de fertilizantes químicos e pretende diminuir ainda mais. Segundo ele: "No futuro penso que não vai mais ser preciso adubo químico. Com a adição de esterco nos piquetes, em 3 ou 4 anos espero poder eliminar o adubo químico". Outro ressalta: "observei os piquetes adubados com adubo orgânico e adubo químico, naqueles que receberam adubos orgânicos as pastagens desenvolveram melhor, mais parelha, eu arisco dizer que as vacas produziram mais leite". Essas falas denotam a compreensão dos agricultores do processo de transição agroecológica e de equilíbrio do solo via adubação mais completa oriunda dos dejetos dos animais ou de adubos orgânicos externos. Segundo Pinheiro Machado (2004), em áreas sob PRV há um expressivo incremento de fertilidade do solo e de melhoria de meio ambiente, se observam processos de desintoxicação do solo pelo aumento da atividade biológica e não uso de agrotóxicos e fertilizantes químicos, aumento da matéria orgânica e disponibilidade de nutrientes.

Em alguns casos observamos que houve um incremento da quantidade de adubo químico no início da implantação do processo. Isso se deve ao fato de que esses agricultores não manejavam as áreas de campo nativo, pois as consideravam de baixa produtividade, periféricas e sem capacidade de resposta à adubação e com a implantação do PRV nessas áreas passaram a investir em adubação. No entanto, praticamente todos os agricultores entrevistados afirmam que esperam atingir o equilíbrio no 
sistema ao ponto de não ser mais necessário utilizar os fertilizantes externos, além disso, observam melhores resultado quando utilizam adubos orgânicos.

Percebemos, também, que hoje os agricultores compreendem o potencial das áreas de campo nativo. Uma fala de um agricultor é representativa desse aspecto: "Eu não oriento ninguém mais a romper um campo para plantar tifton (Cynodon spp). Eu hoje acho que o campo nativo é superior ao tifton, porque quando as vacas estão no campo dão um pouquinho mais, claro que o tifton é uma grande pastagem, não vamos dizer que não. E até o comer delas é diferente, parece que elas gostam mais de campo nativo". Da mesma forma, os agricultores observam que o número de espécies de valor forrageiro do campo nativo tem aumentado nas áreas manejadas sob PRV. Por outro lado, observam a supressão de espécies indicadoras de malesas, como o caraguatá (Eryggium sp), indicadora de terras ácidas e com manejo por queimadas e de alecrim-do-campo (Vernonia nudiflora), indicadora de áreas com excessivo pastoreio e com pouca cobertura vegetal (OVERBECK et al., 2009). Um agricultor, ao falar da mudança da qualidade do campo nativo, afirma que agora está "bonito" de ver a pastagem, porque está "bem verde", tem várias espécies e não tem mais erosão de solo. Esse mesmo agricultor tem uma área com cultivo anual de pastagem e afirma que vai implantar o PRV em toda a área, pois agora são visíveis as diferenças em termos de produtividade, conservação e recuperação de solo.

Outro agricultor comenta: "Uma coisa é as vacas comer só tifton, outra coisa é vim aqui na frente (se referindo ao campo nativo) e comer quicuio, comer grama forquilha, comer pega-pega, comer diversas coisas que tem ali, eu acho que dá bem mais". Esse mesmo agricultor ainda diz: "Eu sou muito fã do campo nativo, até muita gente me pede muda de tifton. Eu digo: pensa duas vezes, se tu quer plantar tifton te dou as mudas, mas eu acho que tifton deve ser plantada em áreas onde faz muitos anos que se usa plantar (se referindo à áreas com culturas anuais), onde vai demorar demais para estabelecer o campo nativo. Eu já rompi campo para plantar tifton, mas me arrependo e não rompo mais". Essas observações dialogam com a Teoria da Trofobiose, segundo a qual a saúde dos organismos é diretamente proporcional ao equilíbrio da nutrição. Para Chaboussou (1999), a manutenção da fertilidade do solo é dependente de fatores quantitativos e qualitativos e não somente da adição de poucos elementos, como é realizado na agricultura convencional. Pinheiro Machado (2004), estudando Chaboussou e as obras de Voisin, escreve que o resultado de um rebanho sadio é diretamente proporcional a uma pastagem sadia e equilibrada, essa por sua vez é resultado de solos bem manejados, férteis e equilibrados.

O manejo ecológico dos solos preconizado, que apresentamos nesse trabalho, tem como base a compreensão dos processos dinâmicos, a preservação e a recuperação das características naturais. Nesse sentido, o principal manejo é a manutenção da cobertura vegetal durante todo o ano, a distribuição do esterco e da urina dos animais em toda a área de exportação vegetal, o não uso de agrotóxicos e a adição de fertilizantes orgânicos nas áreas mais degradadas e com baixa fertilidade, até se atingir o equilíbrio do ecossistema. Outra prática é a roçada da pastagem excedente, para servir de adubação orgânica.

\section{Bem-estar animal, Homeopatia e Fitoterapia}

Um aspecto básico da criação animal de base ecológica é a preocupação com o bem-estar dos animais. Segundo a Organização Mundial para a Saúde Animal (OIE, 2011), o animal está em um bom estado de bem-estar se é saudável, confortável, bem nutrido, seguro, capaz de expressar comportamento inato, e se ele não está sofrendo de estados desagradáveis, tais como dor, medo e aflição. A OIE ainda acrescenta que o bem-estar animal requer prevenção de doenças e tratamento veterinário, abrigo adequado, gestão, nutrição, manuseio e tratamento humanizado.

$\mathrm{Na}$ visão sistêmica da bovinocultura de leite de base ecológica, a homeopatia e a fitoterapia animal, são ferramentas do processo produtivo. Essas complementam os outros elementos que compõem esta proposta, no sentido de equilibrar, de forma global, o organismo dos animais, evitando o aparecimento de moléstias e, também, as tratando quando porventura aparecerem. Percebemos que uma questão fundamental é os agricultores compreenderem, ao utilizar produtos homeopáticos e fitoterápicos, que não se trata de uma simples substituição de insumos. 
A utilização da fitoterapia em SM, ainda é pontual em alguns agricultores, mas há o estímulo à utilização das plantas medicinais para prevenir e tratar algumas moléstias. Estão previstas ações de formações coletivas para organização de pequenos hortos nas propriedades dos agricultores acompanhados. No entanto, observamos que há uma preferência dos agricultores em utilizar a homeopatia, isso se deve à facilidade de uso do medicamento e às observações de rápida eficácia dessa terapêutica.

Segundo Kent (2002), a homeopatia trata do indivíduo como um ser complexo e capaz de reagir às desordens que por ventura acometerem o organismo. Assim, o fundamental é tratar o indivíduo e não a doença, pois o indivíduo equilibrado é um indivíduo sadio. No entanto, em moléstias recorrentes, pode-se fazer o uso de medicamentos que tenham sucesso pontual sobre as mesmas, como é caso da mastite e de infestações por carrapatos (Boophilus microplus), os maiores problemas de sanidade do rebanho, segundo os agricultores entrevistados. No caso dos animais de rebanho pode-se utilizar o conceito de "homeopatia populacional", considerando o grupo como um indivíduo, facilitando, assim, o tratamento. Apontamos como vantagens do uso da homeopatia em rebanhos leiteiros: a melhora global do organismo dos animais; a não indução de resistência dos agentes mórbidos; o preço dos medicamentos homeopáticos em geral mais acessível; facilidade de fornecimento do medicamento que pode ser adicionado no alimento ou sal mineral; inexistência de carência no leite ou derivados; é uma terapia que possibilita a viabilidade de um sistema de produção de base ecológica.

Os medicamentos homeopáticos mais frequentemente utilizados nas propriedades, tanto para o controle de carrapato como para mastite são os chamados Nosódios, que são preparados homeopáticos feitos com o próprio agente causador da doença ou causador do desequilíbrio (CAPA, 2004). Com a evolução da transição agroecológica do sistema de produção, a meta é tratar os animais ou o rebanho como um organismo único. Todos os agricultores que utilizam ou utilizaram a homeopatia em algum momento na propriedade afirmaram que os resultados são visíveis e superiores à alopatia, o que coloca em evidência a importância da ferramenta para o sistema de produção de base ecológica. Como exemplo, em uma das propriedades desse estudo, antes do começo do uso de um composto homeopático para prevenção de mastite foi feito o teste CMT (California Mastitis Test) em todas as vacas em lactação. No teste feito em 08 de abril de 2014 havia 34 vacas em lactação, das quais 30 apresentaram pelo menos um sinal positivo no CMT, ou seja $88 \%$ do total de animais, sendo que $44 \%$ de todos os tetos testados apresentaram positividade. Após 49 dias de tratamento com composto homeopático no sal mineral, de 30 vacas apenas cinco vacas ou $16 \%$ apresentaram CMT positivo e apenas $5 \%$ dos tetos eram positivos.

O PRV quebra o ciclo do carrapato, sendo a principal ferramenta de controle. No entanto, o parasita ainda resiste nos corredores e áreas de descanso perto de matas. Os agricultores entrevistados afirmam que chegaram a banhar o rebanho com produtos carrapaticidas até duas vezes por mês em média no verão. Teve um agricultor que tinha problemas mais sérios de infestação desse parasita e chegou a utilizar o banho carrapaticida uma vez por semana, por um determinado período. Faz mais de um ano que esse agricultor utiliza homeopatia para controle de carrapato e afirma: "O que está combatendo, que no último ano não foi banhado as vacas de leite é através da homeopatia".

Os agricultores observam a diferença entre o manejo extensivo e em PRV, com relação à infestação de carrapatos. A afirmação de um agricultor representa isso: "Esses dias estava observando, fui na propriedade do vizinho e estavam banhando as vacas, estava caindo carrapato, era um 'carrapatéo só'. E a diferença é essa, ele não tem piquete, o gado fica todo junto no campo e o campo sujo, não usa homeopatia, é um 'carrapatéo' só", diz o agricultor. A compreensão do sistema é evidente e os agricultores percebem os avanços que o PRV proporciona. Em todas as propriedades foi relatado que a mastite e a incidência de carrapatos diminuiu com o processo de transição agroecológica.

O conceito das cinco liberdades (livre de fome e sede; livre de desconforto; livre de dor doença e injúria; liberdade para expressar os comportamentos naturais da espécie; livre de medo e de estresse), discutidas por Webster (2005), nos parece adequado para o planejamento do bem-estar animal e é balizador do trabalho desenvolvido com os agricultores produtores de leite de SM. Percebese que o PRV com abundância de forragem, a oferta de sombra e água, a possibilidade do gado pastar livremente, o não uso de injeções contínuas e a ausência de estresse no manejo, garantem as cinco 
liberdades. Outro fator a ser ressaltado é o fato dos animais terem nome e não um número, e serem tratados com humanidade em todas as propriedades.

\section{Relação ser humano-natureza}

Entendemos que a premissa básica para o desenvolvimento de agroecossistemas sustentáveis e agroecológicos é uma nova compreensão da natureza pelo ser humano. Assim, os agricultores precisam desenvolver percepções dos sistemas de produção construídas internamente nas suas propriedades ou através da troca de experiências entre o grupo. Além disso, reafirmar aqueles conhecimentos tradicionais que não foram valorizados pela agricultura moderna.

Uma das principais observações que pode ser realizada nesta categoria de análise é o aumento da confiança dos agricultores no fazer agricultura. Hoje eles fazem e sabem por que fazem, não executam técnicas alheias e descontextualizadas de seus cotidianos e construídas à revelia dos seus agroecossistemas. Apontamos as observações realizadas pelos agricultores de que os animais preferem o campo nativo em relação às pastagens cultivadas ou com relação ao desenvolvimento das espécies implantadas, como alguns dos indicativos dessa relação construída ou re-valorizada. As pastagens implantadas são diferentes em todas as propriedades. Percebe-se que os agricultores fazem consórcio, preferem uma à outra espécie e essas atitudes são tomadas porque esses têm liberdade de experimentar e adaptar as pastagens, considerando as características individuais de seus agroecossistemas. Observamos que, não raro, a preferência dos animais é fator determinante na escolha ou no "melhoramento" das pastagens. Um agricultor afirma que está implantando hemarthria e jiggs em áreas povoadas por tifton, pois percebe que as vacas gostam mais das duas primeiras. Outro diz que vai investir mais no campo nativo, porque as vacas pastam mais nessas áreas.

A adaptação das forrageiras já existentes nas propriedades é outro conhecimento apropriado importante, pois onde havia pastagens perenes implantadas ou nativas, a ação extensionista foi no sentido de aproveitar esse recurso. As mudanças realizadas em termos de melhoramento de pastagens nessas áreas somente acontecem se os agricultores julgarem necessárias. Um agricultor, ao analisar todas as pastagens implantadas em sua propriedade, fez uma análise da qualidade das mesmas: "Eu tenho vários tipos de gramíneas, eu parei com a tifton e fui pegando as melhores que se adaptaram e que as vacas dão mais resultado". O agricultor elegeu três variedades, pois observando o rendimento dos animais e o desenvolvimento das forragens antes e depois do corte, chegou à conclusão que, na sua propriedade, as forrageiras com melhores resultados são a Missioneira Gigante, a Hemarthria e a Jiggs. O agricultor fala: "A Hemarthria é mais agressiva e é mais própria para leite, a Jiggs é mais macia e a Missioneira é guerreira mesmo. Essas as vacas comem até o chão, a tifton e as outras eu preciso roçar depois do pastoreio, porque fica um talão". Esse tipo de observação demonstra o quanto os agricultores estão se apropriando dos conhecimentos construídos e agindo como sujeitos de seus agroecossistemas.

Outro conhecimento que representa a intrínseca relação dos agricultores com os processos naturais é a observação das fases lunares para realizar a inseminação das vacas e novilhas. Dois agricultores entrevistados são detentores desse conhecimento tradicional. Eles realizam a inseminação nas fases de lua cheia e nova, como eles chamam: "na lua redonda". Esse procedimento visa obter maior incidência de crias fêmeas. Se falha o cio e a vaca não "pega cria" (no dizer dos agricultores), esperam passar um cio, pois no segundo cio subsequente a primeira tentativa de inseminação vai ser exatamente "na lua redonda". Um dos agricultores afirma: "Eu cheguei a tirar de 22 crias, 19 terneiras".

A agricultura foi historicamente construída num processo de interação íntima entre os agricultores com os sistemas naturais. Somente muito recentemente na história da humanidade os conhecimentos agrícolas deixaram de ser domínio dos agricultores, para ser de domínio externo à propriedade, principalmente da indústria de insumos. Assim, a relação ser humano-natureza trata, principalmente, do resgate e revalorização dos conhecimentos dos agricultores e da relação sujeitosujeito na ação extensionista. 
Reprodução social

O sistema de produção agroecológico aqui proposto deixa de ter sentido se não produzir renda e modos de vida capazes de manter os agricultores no campo com dignidade. Embora reconheçamos os ganhos ambientais dos agroecossistemas sustentáveis e a produção de um alimento de melhor qualidade, o agricultor é central nessa proposta. Os agricultores, quando questionados sobre as principais mudanças percebidas a partir do desenvolvimento do sistema, apontam o trabalho e a renda. Um agricultor afirma: "Eu resumo tudo em uma afirmação, eu queria ser 20 anos mais novo, pra poder aproveitar melhor todas as mudanças implantadas na propriedade". Outro agricultor diz: "Agora com os piquetes eu trabalho bem menos, o meu trabalho melhorou 100\%. Tem pastagem em todas as épocas do ano, água nos piquetes, não preciso mais arrancar mandioca e cortar cana para animais no inverno". Os agricultores afirmam que o trabalho e o compromisso diário ainda existem, o que mudou radicalmente é a penosidade do mesmo e a organização interna da propriedade. Uma agricultora afirma: "Agora com os piquetes e com as mudanças realizadas eu vou poder me dedicar a outras atividades. Quero fazer feira, pois não precisamos ficar os dois o tempo inteiro na lida com o leite". Cabe salientar que todas as famílias estudadas desenvolviam um sistema de produção altamente demandante de trabalho.

O segundo fator é a renda, que aumentou consideravelmente em todas as famílias estudadas, embora haja uma que ainda está em processo de estabilização, já que necessitou de muitos investimentos iniciais e apresentava agroecossistemas bem degradados. Mesmo nessa família, o agricultor afirma estar ciente dos ganhos, pois está renovando todo o plantel, já tem toda a área com pastagem perene e piqueteada, com água nos piquetes e com as arbóreas implantadas. Além disso, fez investimentos em uma sala de ordenha, trator, roçadeira e ordenhadeira. Mesmo que a renda líquida tenha sido baixa e em alguns meses, negativa, o agricultor entende que é um processo e que o sistema dele estava muito impactado antes de ingressar no projeto. $\mathrm{O}$ agricultor afirma: "No nível que eu estou hoje, mesmo que eu ainda esteja pagando muitas dívidas, de agora em diante as coisas só vão melhorar".

A história e relato dessa família, assim como de outras, demonstra a convicção dos agricultores no processo de transição. Os investimentos realizados em todas as propriedades são um indicativo da melhoria do sistema de produção e da segurança dos agricultores, os quais afirmam que antes a atividade leiteira não fornecia margem para investimentos. Em praticamente todas as propriedades os agricultores acessaram crédito rural via PRONAF para investimento na aquisição de equipamentos e construção de instalações. Algumas famílias afirmam que o próximo passo vai ser investir nas moradias, pois com a melhoria da renda terão recursos para melhorar o conforto da família.

Muitos afirmam que, antes do projeto, não gostariam que os filhos ficassem no meio rural. Hoje a percepção com relação aos jovens é completamente diferente, em uma família houve o retorno de um filho para trabalhar na propriedade, enquanto em outras os agricultores estão preparando os filhos para assumir a atividade. No entanto, existem algumas propriedades onde não há mais possibilidade de sucessão. Os agricultores lamentam não ter tido acesso a esse processo mais cedo, assim teriam investido na permanência dos filhos e não no contrário. Em uma das famílias, os membros fazem rodízio de trabalho nos fins de semana, assim alguns tem folgas programadas enquanto os outros assuem as atividades da propriedade. Essa família organizou de tal forma o trabalho que foi possível os membros tirar férias de forma intercalada, fato que nunca acontecia.

Cabe ressaltar o amor dos agricultores pela atividade agrícola e a satisfação manifesta por estarem vivenciando algo que não acreditavam existir na atividade leiteira: mais renda e menos trabalho. Aliar a produção agroecológica com renda capaz de garantir vida digna aos agricultores, com a possibilidade de uso dos recursos disponíveis nas propriedades e desenhar uma perspectiva para os jovens no meio rural, parece ser um avanço na proposta estudada e, talvez, um referencial para o redesenho de outros sistemas de produção. A reprodução social dos agricultores passa pela perspectiva de um rural no qual os sujeitos que lá vivem e trabalham, vivam como sujeitos de sua própria história. 
Considerações finais

A transição agroecológica dos sistemas de produção de leite de Santa Maria demonstra duas questões centrais: 1) Os referenciais que compõem o sistema agroecológico; 2) A importância de uma extensão rural capaz de realizar uma ruptura, bem como a libertação dos agricultores dos sistemas de produção convencionais e de estabelecer processos contínuos em vez de uma ação fragmentada e pontual. A proposta central da ação extensionista é empoderar os agricultores, dar liberdade a eles e não os escravizar, tornando-os dependentes da ação externa. As potencialidades do sistema de produção agroecológico de leite são alcançadas com as ferramentas presentes nas categorias de análise PRV; manejo de agroecossistemas; manejo ecológico de solos; bem-estar animal, homeopatia e fitoterapia; relação ser humano-natureza; e reprodução social. Do ponto de vista tecnológico do processo em questão, o PRV compõe o pano de fundo desse sistema, sendo complementado com o manejo do agroecossistema e do solo, assim como as ferramentas e princípios que garantem o bemestar animal. Entretanto, no processo os agricultores são centrais, assim a relação ser humano-natureza e a reprodução social mostram a importância da apropriação e construção do conhecimento, assim como a viabilização econômica e social das famílias.

\section{Referências}

ACOSTA, A. C., et al. Mastites em ruminantes no Brasil. Pesq. Vet. Bras. v. 36, n. 7, p. 565-573, 2016.

ALTIERI, M.. Agroecologia: Bases científicas para uma agricultura sustentável. 3.ed.rev.ampl. São Paulo: Expressão Popular; Rio de Janeiro: AS-PTA, 2012.

ALTIERI, M.; NICHOLLS, C. L. Agroecologia y resiliencia al cambio climático: princípios e consideraciones metodológicas. In: NICHOLLS, Clara L.; ALTIERI, Miguel. Agroecolía y cambio climático: metodologías para evaluar la resiliencia sico-ecológica em comunidades rurales. p. 7-20, 2013.

CAPA. Homeopatia simples: alternativa para pequenos agricultores. Maringá, PR: Centro de Apoio ao Pequeno Agricultor, 2004.

CARVALHO, M. M.; XAVIER, D. F. Sistemas Silvipastoris para Recuperação e Desenvolvimento de Pastagens. In: AQUINO, Adriana Maria de, ASSIS, Renato Linhares de. Agroecologia: princípios e técnicas para uma agricultura orgânica sustentável. Brasília, DF: Embrapa Informação Tecnológica, 2005. p.497-514.

CASSELL, B.; MCALLISTER, J. Dairy Crossbreeding Research: Results from Current Projects. Virginia Cooperative Extension, n. 404, v. 094 2009. Disponível em: <encurtador.com.br/evBV5>. Acesso em 01 fev. 2019.

CHABOUSSOU, F.. Plantas doentes pelo uso de agrotóxicos: a teoria da trofobiose. - 2 ed.- Porto Alegre: L\&M, 1999.

EMATER. Rio Grande do Sul/ASCAR. Relatório socioeconômico da cadeia produtiva do leite no Rio Grande do Sul: 2017. Porto Alegre RS: Emater/RS-Ascar, 2017. 64 p

FAO. Faostat: statistics division, trade, download data, crops and livestock products. 2017. Disponível em: < http://www.fao.org/faostat/en/\#data/QL>. Acesso em: 8 nov. 2018.

FRANÇA, C. G. de; DEL GROSSI, M. E.; AZEVEDO, V. P. M. de M.. O censo agropecuário 2006 e a agricultura familiar no Brasil. Brasília: MDA, 2009.

FRANKE, I. L.; FURTADO, S. C.. Sistemas silvipastoris: fundamentos e aplicabilidade. Rio Branco: Embrapa Acre, 2001. (Embrapa Acre, documentos n. 74)

GLIESSMAN, S. R. Agroecologia: processos Ecológicos em Agricultura sustentável. Porto alegre: editora Universidade/UFRGS, 2000.

GOMES, R. Análise e interpretação de dados de pesquisa qualitativa. In: DESLANDES, S. F.; GOMES, R. MINAYO, M. C. de S. (org.). Pesquisa social: teoria, método e criatividade. - 31. Ed- Petrópolis, RJ: Vozes, 2012. p. 79-108.

INSTITUTO GAÚCHO DO LEITE (IGL); EMATER. RIO GRANDE DO SUL/ASCAR. Relatório socioeconômico da cadeia produtiva do leite no Rio Grande do Sul. Porto Alegre, RS: Emater/RS-Ascar, 2015. 76p.

KENT, J. T.. Filosofia homeopática. São Paulo: Rode Editorial, 2002.

KOHEK JUNIOR, I. Por que o seu tratamento contra o carrapato pode estar falhando! Porto Alegre: DDA, Secretaria Estadual de Agricultura e Pecuária, 2015. 8p. (Informativo Técnico DDA, n. 5)

MAIA, G. B. da S. et al. Produção leiteira no Brasil. In: BNDES. Agropecuária: BNDES Setorial n. 37, 2013. p. 371398. Disponível em: <encurtador.com.br/vwzSX>. Acesso em 15 nov. 2018.

MAPA. Valor Bruto da Produção Principais Produtos Agropecuários. Brasília: MAPA, 2018. Disponível em: < http://www.agricultura.gov.br/>. Acesso em 11 nov. 2019.

OVERBECK, G. E, et al. Os Campos Sulinos: um bioma negligenciado. In: PILLAR, Valério de Patta et al. (Editores). Campos Sulinos - conservação e uso sustentável da biodiversidade. Brasília: MMA, 2009. p. 26-41 
PERES NETO, F.; ZAPPA, V. Mastite em vacas leiteiras-revisão de literatura. Revista Científica Eletrônica de Medicina Veterinária, v. 9, n. 16, 2011.

PINHEIRO MACHADO, L C. Pastoreio Racional Voisin: tecnologia agroecológica para o 3. milênio. Porto Alegre: Cinco continentes, 2004.

PRIMAVESI, a. m. Manejo Ecológico do solo: agricultura em regiões tropicais. São Paulo, Nobel,1999.

SERAMIM, R. J.; ROJO, C. A. Gestão dos custos de produção da atividade leiteira na agricultura familiar. Revista Gestão \& Tecnologia, v. 16, n. 3, p. 244-260, 2016.

THALER NETO, A.; et al. Desempenho produtivo de vacas mestiças Holandês x Jersey em comparação ao Holandês. Revista de Ciências Agroveterinárias, Lages, v.12, n.1, p. 7-12, 2013.

WEBSTER, J. Animal Welfare: Limping Towards Eden. Oxford, UK: Blackwell Publishing Ltd, 2005.

WORLD ORGANISATION FOR ANIMAL HEALTH (OIE). Terrestrial Animal Health Code. Volume I General provisions. 20. Ed. France: OIE, 2011. 